\title{
India, Open Access, the Law of Karma and the Golden Rule
}

\author{
Stevan Harnad \\ Canada Research Chair, Institut des sciences cognitives, Université du Québec à Montréal, Canada \\ University of Southampton, UK \\ http://www.eprints.org/openaccess/
}

and

\author{
Alma Swan \\ Key Perspectives Ltd, Truro UK (www.keyperspectives.co.uk) \\ School of Electronics \& Computer Sciences, University of Southampton, UK \\ Warwick Business School, University of Warwick, UK
}

India is peculiarly positioned to help herself while helping the entire planet as well. There are Haves and Have-Nots in every domain, and research is no exception: Some have more access to laboratories, equipment, grants, and research literature, and some have much less. Laboratories, equipment, and even research funding are analog. They are physical resources that are finite and unequally distributed. But the research literature is digital and, both in principle and practice, it could be made freely and equally accessible to one and all. And very much hangs upon its equal distribution, because research productivity and progress depend critically on having full access to current and past research findings. They are what current and future research is built upon, and from.

About 25,000 research journals exist across all fields of science and scholarship, the world over, in all languages. They publish about 2.5 million articles a year. Access to those articles is very unevenly distributed. There are Haves and Have-Nots among the planet's universities and research institutions, but even the Haves can only afford a fraction of the whole. Even Harvard, the university with the largest journals budget of all, cannot subscribe to them all, and most other universities have far smaller journal budgets.

Yet the irony is that the authors of all those articles - researchers - have always given them away for free. They give them to their publishers, asking for no fee or royalty from their sales in return; they also give them away for free to anyone who writes to them requesting a reprint: In paper days this requesting and sending was by mail; in online days it is increasingly by email.

To Indian researchers, requesting reprints by mail has always been critical, as India of course is very much on the Have-Not end of the world's journal subscriptions.

Requesting and sending reprints certainly comes nowhere near solving the problem of providing equal access to all for all, but it has been a godsend for some, and as a result, India is not just a net consumer of research from the rest of the world, but also a significant provider of research to the rest of the world. The question to be asked in the online age, however, is whether email reprint requests are enough to provide the 
research access that India needs, and whether India's research output is getting all the impact it deserves. The answer is no: India can do far better than that.

Research impact means research uptake, applications and citations. Researchers should always ask themselves: to what extent are my findings being read, used, and built upon, in further research and research applications? We are accustomed to thinking of the lack of access to research as being a handicap for the research consumer, but it is a handicap for the research provider as well. Less accessible research is also research that is failing to achieve its full potential impact. And research impact brings visibility, funding, new collaborations and further research progress.

Yet the online age has already provided the means to solve both the research access and the research impact problem completely: Instead of having to mail or email authors to request reprints of articles, one by one, researchers can access the 'eprint' of the article directly, free for all ('Open Access', OA), on the web. Or at least they could do so, if the 2.5 million annual articles were all being deposited ('self-archived'), free for all, on the web. The problem is that only about $15 \%$ of them are currently being selfarchived spontaneously by their authors.

Open Access has been demonstrated to increase research impact dramatically: the percentage increase in citations in traditional (subscription-only) journals that are made Open Access through self-archiving by their authors (compared to articles that are not) is shown in Figure 1 for a number of disciplines (Harnad \& Brody, 2004, Hajjem et al. 2005). India spends about 170 billion rupees of public money annually on science and technology research. The return on this investment must be maximised: it is the duty of research administrators to ensure this. Let us take the data in Figure 1 to indicate that Open Access increases citations to published research on average by over $50 \%$. Since only $15 \%$ of research is available on this basis, this means that the remaining $85 \%$ stays hidden away in subscription-based journals that only a minority of libraries can purchase; they thus remain largely unread and unused. That $85 \%$ could be getting far greater visibility and use if it were all Open Access. In other words, India would have to spend a further 70 billion rupees on research to get the same impact on the world stage as it could currently get for no more money simply by making all of the country's research output Open Access.

For the Fellows of INSA, the personal gain in visibility and impact for their work is also there to be gained. An INSA repository, established using the free software available from EPrints ${ }^{1}$, for example, would collect and display the work of its Fellows to the world. Every time Fellows have a completed manuscript that has been peer-reviewed they deposit it in the repository and as soon as this is done it becomes visible and usable by all. Fellows will be able to check the number of times an article has been downloaded and read from the repository because the software can report these figures, as well as indicating the institutions that readers are from. A new world of personal management of research dissemination and monitoring is now possible for

\footnotetext{
${ }^{1} \mathrm{http}: / / \mathrm{www}$.eprints.org/software/
} 
Fellows of INSA once a repository is available to them -- and an official INSA deposit mandate is adopted.

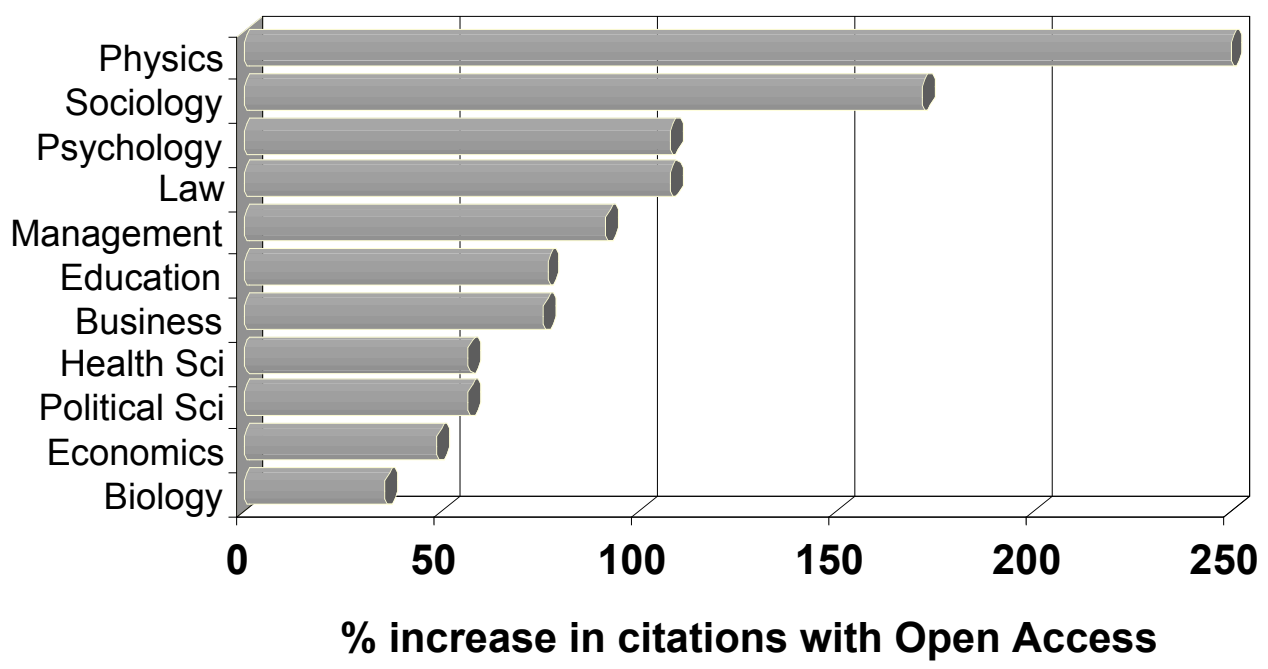

Figure 1: Percentage gain in citations for Open Access articles compared to Closed Access counterparts in the same issue of the same journal (from Harnad \& Brody, 2004; Hajjem et al. 2005)

So what is India doing about Open Access? India has already made important contributions to the growth of OA, thanks to the efforts of its tireless advocate, Subbiah Arunachalam, as well as the invaluable initiatives of Prof. N. Balakrishnan and the late T.B. Rajashekar, who created one of India's first OA repositories at the Indian Institute of Science, and did a great deal to encourage self-archiving by IISc's researchers. Articles are self-archived into digital repositories maintained by research-based institutions. Open Access repositories are either centralised subject-based depots or are broad-based institutional depots for electronic articles. They comply with a shared set of standards (OAl: Open Archives Initiative) that make them interoperable, forming in effect a worldwide database of research. Google and Google Scholar index Open Access repositories so any articles in them are assured of the best visibility. There are around 1000 Open Access repositories across the world. India already has 24 repositories, 19 of them institutional. The biggest is IISc's, with around 7500 documents deposited to date.

But creating archives and 'archivangelising' (advocating) are not enough. Researchers the world over are largely unaware of the advantages of Open Access and need to be informed and encouraged by their employers and funders. In several surveys they have indicated that they will willingly self-archive their articles if their institutions and/or their funders mandate it (Swan, 2005). Hence there is now a worldwide movement toward mandating OA self-archiving. Most of the UK Research Councils, the Wellcome Trust, the National Institutes of Health, the European Research Council, the Deutsche Forschungsgemeinschaft (German Research Council), and many other funders and universities now have such mandatory policies. In India, too, this is happening. One of the 11 institutional OA self-archiving mandates so far adopted worldwide is Indian 
(National Institute of Technology, Rourkela) and there is also an Indian governmental recommendation from the National Knowledge Commission to mandate OA as a condition of research funding (out of 14 funder mandates adopted and 4 more recommended, worldwide). India has also hosted the workshop that produced the Bangalore Policy Statement, a draft National OA Policy for Developing Countries (see references).

This is already an impressive record, but India could do so much more, so easily. India needs to adopt a national OA self-archiving mandate for all of its research institutions and funders. The principle is simple, it is already embodied in India's Law of Karma as well as in the West's 'Golden Rule': 'Self-Archive Unto Others As You Would Have Them Self-Archive Unto You'. If India sets the example, by officially adopting and implementing this rule, India's own research access and impact will be maximised, the rest of the world will follow India's example, and research progress worldwide will be the beneficiary.

Thanks to Barbara Kirsop and Leslie Chan of the Electronic Publishing Trust for Development for helpful comments during the writing of this article.

\section{References and further reading} May 52005.

Arunachalam, Subbiah (2006) Why India Needs Open Access. Open And Shut. http://poynder.blogspot.com/2006/05/why-india-needs-open-access.html

Chan, L, Kirsop, B and Arunachalam, S (2005) Open access archiving: the fast track to building research capacity in developing countries. Science and Development Network. pp. 1-13.

http://openmed.nic.in/1134/

Hajjem, C., Harnad, S. and Gingras, Y. (2005) Ten-Year Cross-Disciplinary Comparison of the Growth of Open Access and How it Increases Research Citation Impact. IEEE Data Engineering Bulletin 28(4) pp. 39-47.

http://eprints.ecs.soton.ac.uk/12906/

Harnad, S. \& Carr, L. (2000) Integrating, Navigating and Analyzing Eprint Archives Through Open Citation Linking (the OpCit Project). Current Science 79(5): 629-638.

http://www.ias.ac.in/currsci/sep102000/629.pdf

Harnad, S and Brody, T (2004) Comparing the impact of open access (OA) vs. non-OA articles in the same journals. D-Lib Magazine, 10 (6), (www.dlib.org/dlib/june04/harnad/06harnad.html).

Harnad, Stevan (2006) Promoting Open Access to Research. The Hindu.

November 12006.

http://www.hindu.com/2006/11/01/stories/2006110104991100.htm

National Open Access Policy for Developing Countries. Indian Institute of Science. Bangalore. 3 November 2006.

http://www.ncsi.iisc.ernet.in/OAworkshop2006/pdfs/NationalOAPolicyDCs.pdf

Swan, Alma (2005). Open Access self-archiving: An introduction

http://eprints.ecs.soton.ac.uk/11006/01/jiscsum.pdf

Suber, Peter \& Arunachalam, Subbiah (2005) Open Access to Science in the Developing World. World-Information City. October 17, 2005.

http://www.earlham.edu/ peters/writing/wsis2.htm 